\title{
LOUCURA NA SOCIEDADE DOGON - REPÚBLICA DO MALI*
}

\author{
MENTALLY IN THE DOGON SOCIETY - \\ MALI REPUBLIC
}

\author{
Denise Dias Barros ${ }^{(1)}$
}

BARROS, D.D. Loucura na sociedade dogon - República do Mali. Rev. Ter. Ocup. Univ. São Paulo, v. 13, n. 2, p. 64-70, maio/ago. 2002.

\begin{abstract}
RESUMO: Com base em pesquisa de campo realizada entre 1994 e 1996 nas terras dogon, Sociedade Negro-africana da República do Mali (África do Oeste), observa-se que sociedade dogon possui um léxico significativo vinculado à designação e à compreensão da loucura. Possui, por outro lado, um conjunto de saberes organizados, exercido sobretudo por homens, que se transmite de uma geração a outra dentro da linhagem paterna ou que se adquire, principalmente, por revelação. Estes saberes referem-se ao uso de plantas, de minerais, de processos rituais e de encantações que se articulam segundo as proposições e práticas históricas Dogon num processo constante de formação da pessoa-dogon e da sociedade. A pessoa considerada louca poderá conhecer destinos diferenciados: será acolhida, tratada e reinserida nas esferas das relações sociais, ou será tratada sem conseguir uma reinserção total, permanecendo aos cuidados de um parente ou amigo. Ela poderá, ainda, ser aprisionada em sua casa ou ser deixada errante, sendo nestes casos encontrada nos mercados, nos povoados e nas estradas.
\end{abstract}

DESCRITORES: Etinopsicologia. Transtornos mentais. Saúde mental. Cultura. Terapia ocupacional/tendências.

\section{Nas trilhas da pesquisa}

$\mathrm{E}$ stivemos pela primeira vez no Mali em 1993, durante a realização de um Seminário sobre Medicina Tradicional no qual se reuniram notáveis da medicina originária de várias regiões do país. O trabalho de campo que viríamos a desenvolver - entre setembro de 1994 a agosto de 1996 - pode então ser acordado com a Divisão Nacional de Medicina Tradicional.

No final das águas de 1994 iniciamos nossas atividades a partir da vila de Bandiagara. Depois de

\footnotetext{
* As pesquisas de campo que formam a base empírica deste artigo foram financiadas pelo CNPq (1994-96) e pela FAPESP (20002001).

(1) Doutora em Sociologia pela FFLCH-USP. Professora do Centro de Docência e Pesquisa em Terapia Ocupacional do Departamento de Fisioterapia, Fonoaudiologia e Terapia Ocupacional da Faculdade de Medicina - USP.

Endereço para correspondência: Rua Cipotânea, 51. Cidade Universitária. São Paulo, SP. CEP: 05360-160.
} 
algumas visitas (que duravam, às vezes, dias) e com base na leitura dos trabalhos de Piero Coppo e de sua equipe, pudemos elaborar roteiros de entrevistas no intuito de apreender as idéias e maneiras de conceber a loucura. Sem a possibilidade de compreender a língua, a proposta de uma observação, compreensão e participação nas conversas do dia-a-dia ficava prejudicada. Os limites faziam-se impiedosamente presentes a cada momento. Aprendemos a aguçar os sentidos: gestos, olhares, tom de voz, tudo era preciso estar atento a tudo para garantir alguma comunicação. Com o tempo as saudações diárias e palavras chaves foram sendo incorporadas mas a barreira lingüística permaneceu uma importante limitação deste estudo. Optamos por registrar as conversações, transcrevê-las e traduzi-las. O registro das informações foi negociado com cada uma das pessoas que reagiam diversamente à proposição. Algumas pessoas demoraram vários encontros até sua permissão para gravar conversações, fotografar ou filmar.

Trabalhar em equipe foi fundamental pois nos constringiu a confrontação da observação e a explicitação de objetivos e métodos, facilitando, ainda, uma percepção mais abrangente. Assim, as informações e as interpretações são frutos de redes de interações multiformes.

Seguindo a orientação de Hampâté Bâ que enfatiza a necessidade de que a cultura seja apreendida pela experiência, precisávamos ir além da busca de informações (enquanto dados objetivados); era fundamental aprender as regras de comportamento que guiam as relações e o dia-a-dia das pessoas.

Para Hampâté Bâ, no mundo africano, o intermediário, isto é, a mediação é indispensável. Entre o criador e a humanidade existem intermediários. $\mathrm{O}$ africano passa sempre por um intermediário, o irmão mais novo para se dirigir a seu pai, solicitará a mediação de seu irmão mais velho, de sua mãe ou, ainda de sua tia. Se uma pessoa for a uma reunião, deverá encontrar alguém que exponha, em seu nome, o motivo de sua presença. A palavra é o melhor dos intermediários mas a palavra não aceita três coisas: ela não aceita ser pronunciada antes do tempo, ela não aceita não ser pronunciada quando chega o momento e ela não aceita ser pronunciada após o momento. Assim, diz-se que o tempo está dentro do segredo de três. Esse pensamento triádico, avesso às binaridades e às linearidades constitui, em nossa visão, a base do pensamento dogon (e talvez negro-africano); suas conseqüências são apreendidas com grande dificuldade, permanecendo fugazes e escorregadias para a racionalidade ocidental.

O que significa wede-wede na sociedade dogon*? Loucura? O que ocorre com a pessoa que, rompendo a barreira do mal-estar em sua civilização passa a não ter suas atitudes, gestos, palavras toleradas pelos seus? Foram estas algumas das questões e inquietações que conduziram nossa busca da palavra dos diferentes atores que contracenam, na vida cotidiana na sociedade dogon (República do Mali).

A loucura é vista, aqui, como uma manifestação das possibilidades do humano, sendo ao mesmo tempo singular por se constituir em acontecimento particular na vida de uma pessoa e coletiva por exigir sentidos compartilhados. Não se trata de discutir o que ela é, mas como é compreendida e vivida.

\section{Universo terapêutico dogon}

Sow (1977, p. 86) distingue três dimensões constitutivas da pessoa. A primeira é a articulação da pessoa com o ancestral fundador que confere a ela sua dimensão fundamental (p. 87). A segunda, a articulação da pessoa na comunidade cultural atual que configura o lugar de cada um, as relações das pessoas entre si, as regras, as instituições, as práticas sociais, além da relação dos homens com a natureza. Uma terceira dimensão é dada pela existência da linhagem, que confere à pessoa o sentimento de existir dentro da segurança da família e, ao mesmo tempo, propicia um pertencimento em que as implicações relacionais são máximas (p. 88-9). Neste sentido, "dentro e fora da África o Negro coloca o problema da identidade coletiva, qualquer que seja o interesse científico que se lhe conceda, como importância vital. Está no cerne dos debates neste terreno de sua própria existência como homem particularizado e concreto" (COELHO apud MOURÃO, 1995/96, p. 9).

A noção de saúde é entendida com parte do processo de formação e de socialização da pessoa; processo este que se realiza na intersecção entre a pessoa e seus ancestrais, entre a pessoa e a comunidade, desenvolvendo-se a partir de um processo existencial constituído por meio de percursos e

\footnotetext{
*Nome pelo qual ficou conhecido o complexo cultural negro-africano que ocupa a região noroeste da República do Mali, África do oeste
} 
elaborações que lhes são singulares.

A criança nasce com tudo o que compõe o humano, mas inicia um processo que irá fazer dela pessoa. A ação constante da sociedade na construção da pessoa conhece momentos de síntese. Esse processo cumpre-se por meio de rituais individuais e coletivos. A pessoa deverá crescer, adquirir força e saber num processo que não concebe rupturas, e exige confirmações constantes entre os percursos pessoais e a dinâmica social. Eventos específicos podem interferir colocando em risco a integridade e portanto a saúde: acidentes, doenças, enganos, transgressões e influência de outros seres. O princípio de interferências entre os seres é uma característica importante da interpretação de mundo dogon. Trata-se de uma representação plural cuja característica principal é ser essencialmente relativa e relacional (AUGÉ, 1994, p. 32).

As pessoas são definidas num sistema de relações cujos parâmetros mais significativos são a filiação e a aliança. Desde sua concepção, a criança permanece alvo de inúmeros perigos, sua sobrevivência é incerta. Sonhos ou acontecimentos inesperados são portadores de mensagens a serem decifradas. A adivinhação permite tecer interpretações que apaziguam a dor provocada pelo medo e pela angústia e facilita os processos de tratamento e a cura.

Não um, mas diversos adivinhos são procurados a cada inquietação, desentendimento ou diante de um desejo ou ambição. Em sua busca de sentido a pessoa permanece envolvida pela incerteza. Adivinhos, terapeutas especialistas no tratamento da loucura e marabus* acolhem todo tipo de ansiedade e vão contribuindo para sua elaboração. A doença é percebida como perturbação do equilíbrio que é preciso reconstituir. Deve-se agir sobre diversos níveis para recompor a ordem: a purificação do corpo do doente e a reparação da falta são condições necessárias para que um tratamento possa ser eficaz.

Diante de uma experiência de crise, as primeiras reações ocorrem, mais freqüentemente, no seio da família extensa-gin'na. É a partir da gin'na que nascem a solidariedade e a ajuda, mas também, a rejeição e o abandono da pessoa que adoece pois quando uma crise individual emerge, ela evoca a presença de conflitos nas relações entre os mais próximos. Os recursos que são postos em ação pela família, amigos, adivinhos, marabus e terapeutas tornam possível reconduzir a pessoa a si mesma e à sua coletividade. Se uma pessoa sofre processos de rejeição pelo grupo doméstico, ela pode ser acolhida por membros da família extensa, por amigos ou pelo próprio terapeuta. Econtramos, também, pessoas abandonadas ou deixadas entregues à errância nas estradas e nos mercados. O itinerário de busca da compreensão do mal e de sua reorientação não é linear, mas, um processo dinâmico que envolve dor e as ambigüidades próprias aos caminhos humanos. É neste contexto que a busca de sentido integra o processo terapêutico e o diagnóstico a terapia. A ordem da escolha dos terapeutas (familiares e não) e dos adivinhos não deve ser lida de forma estática, mas, como possibilidades que podem ser utilizadas de múltiplas maneiras e em sequiência diversificadas.

\section{Terapeutas}

Diversos são os agentes socais que formam o sistema terapêutico dogon. Frente ao sofrimento, um primeiro nível de reações ocorre no seio da família.

$\mathrm{Na}$ sociedade dogon convivem diferentes maneiras de ser terapeuta e as terapias são também diversificadas. Existem interfaces importantes com valores e práticas islâmicas. Podemos distinguir os adivinhos (almaga **, kundu-n\&), os terapeutas $(j<n-j<\# u-n \&)$, os vendedores de plantas medicinais e objetos destinados aos tratamentos e rituais terapêuticos, os encarregados de cultos, os guardiões de objetos ou lugares-receptáculos de forças. Não podemos deixar de mencionar o marabu que trata utilizando o Corão.

O terapeuta conhece, também, a farmacopéia pertinente e a palavra que dinamiza sua ação terapêutica. Ele é reconhecido como aquele que tem o poder de curar e recorre à sua sensibilidade, podendo fazer uso de alguma técnica de adivinhação ou de comunicação com os seres não visíveis. O que caracteriza a ação do terapeuta dogon é o conjunto de sua intervenção: ritos, palavra, uso de vegetais, minerais e animais, a autoridade e a qualidade da própria presença. Tudo isto

\footnotetext{
* Aquele que, entre os muçulmanos, dedica-se à prática e ao ensino da vida religiosa e à leitura do Alcorão.

** A etimologia da palavra proposta por Calame-Griaule é que almaga, derivaria de álu mánga, literalmente "petri l'indecision" ou seja acabar com a indecisão (1965, p. 430). Outra explicação nos foi dada: alu significaria aliança e manga, guardar nas mãos, ou seja, dar forma, criar).
} 
sem cindir as dimensões existenciais da pessoa, os vínculos que estabelecem seu pertencimento a uma família, aos ancestrais e, portanto, à sociedade dogon.

\section{Noções ligadas à loucura}

Wede-wede, loucura, é classificada pelos dogon como uma doença $(l u l<)$ grave. Para definir uma situação considerada patológica encontra-se terminologia própria em diferentes línguas dogon, tratase de wede-wede (donno $\mathrm{s}<$ ); keke (te\#u kã); wezenin $(\mathrm{t}<\mathrm{r}<\mathrm{s}<)$ entre outras.

Quando uma pessoa é chamada de wede-wede gin\&, significa que se considera estar diante de uma situação onde a recuperação é difícil. Decorre daí o cuidado na utilização deste termo. É preferível usar formas figuradas para fazer referência a uma situação de crise como "pessoa com cabeça incompleta" (ind\& $k u k \& w w<l<$ ); "pessoa com cabeça que se inverte" (ind\& $k u$ bilia $d \&$ ); " pessoa com cabeça que se espalha (ind\& ku ginna $w<$ ).

A doença, como noutras culturas negro-africanas, é uma entidade que se movimenta, isto é, sobe, desce, passeia, viaja, enfim, age. Sendo assim, para dizer que a pessoa ficou doente diz-se: a doença montou sobre sua cabeça $(l u l<k u w<m<$ ra dambe); a doença o prendeu (lul $<$ won agi); a doença sentou em sua cabeça (lul $<k u m<n \&$ da\#a). Mas, a loucura não 'monta' em qualquer pessoa. Os dogon consideram que as pessoas de cabeça leve (ind\& ku wey) que expressam de forma marcante suas emoções e têm medo facilmente, estão mais expostas aos perigos da doença enquanto que aquelas consideradas de cabeça pesada $(k u$ dogozo), estão mais protegidas. Estas últimas estão menos expostas ao medo, $n \&$, que é um fator desencadeador de crise. Sendo assim, raramente sofrerão de wede-wede. A qualidade do sangue (doce ou amargo) representa, também, fator importante. Em outras palavras, a doença pode atingir (ind\& $l u l<a g a)$ mais facilmente a pessoa que possui sangue doce ( $n i$ $\& l l u$ ) que é leve (ni wei). O contrário ocorre se a pessoa que possui sangue amargo ( $n i$ gallu) que é pesado ( $n i$ dogod <) como descreveu Lionetti (1994, p. 7-8). Estas condições individuais são consideradas hereditárias e transmitidas de uma geração à outra, mas existem circunstâncias ou eventos de vida que podem fragilizar a pessoa (diminuição da força vital), deixando-a mais exposta às doenças.

Quanto ao comportamento durante a crise, encontramos wede-wede ya (forma femina considerada como manifestação forma fria, kellu) e wede-wede ana (masculina considerada como quente, numo). Coppo afirma que esta tipologia está ligada a idéia de gravidade do evento, sendo a forma ya menos efusiva porém de tratamento mais difícil e a forma ana menos grave e de prognóstico favorável (COPPO, 1994, p. 53-4).

Às vezes, a designação do problema psíquico constrói-se por referência ao agente causal presumido ou a um mediador da ação deste agente. É o caso dos termos $g \& z \&$ (vento), $g \& z \&$ paz\& (vento ruim), ogulum $b \& l \& n$ (seres da mata), $y \& b \& n g \& z e$ ( $y \& b \& n$ que viaja através do vento), $y \& b \& n t \& b i l i *$ (apanhar de $y \& b \& n$ ), $y \& b \& n$ nindimi ( $y \& b e n$ o assustou). É importante assinalar que a classificação que utilizamos é uma inferência dos dados recolhidos, não se trata de sistematização fornecida diretamente pelos terapeutas. Estes, espontaneamente, ao mencionar a tipologia dos problemas psíquicos, preferem fazer alusão à gravidade e ao comportamento do doente do que à causa da doença, preferem enumerar as causas que conhecem sem preocupar-se em agrupá-las ou hierarquizá-las.

$\mathrm{Na}$ loucura, momento de rompimento e de perda dos fatores de proteção, a pessoa vê enfraquecida a relação entre seus diferentes componentes que se dispersam. São os códigos de conduta que fornecem os parâmetros que permitem distinguir normalidade de anormalidade, isto é, são os sinais que permitem entrever um possível sinal de crise. A desordem pessoal pode dar lugar ao desrespeito aos códigos de conduta interpessoais (gritar com e mais velho ou interromper sua palavra, vestir-se inadequadamente ou ficar nu em lugar público, roubar, agredir sem razão, fazer medo nas crianças, fugir para a mata), à violação de um pacto ancestral (penetrar em lugar sagrado, transgressões alimentares), à violação dos preceitos que regem as relações dos homens com a natureza visível (cortar árvore em lugar sagrado, falta no cumprimento dos ritos de purificação da mata) e com os seres não visíveis (penetrar em locais onde vivem seres não visíveis como os $y \& b \& n$, jinnu sem pronunciar as palavras de proteção).

A crise pode também ser identificada por sinais como busca de isolamento, incoerência verbal, mutismo, inapetência acentuada, negativismo, estereotipias,

\footnotetext{
*Além dos $y \& b \& n$ outros seres não visíveis podem agir, isto é, assustar, bater, trata-se dos ginaji, jinu, andumbunlun entre outros, sobre os quais apresentamos aqui uma discussão no item "ogulun $b \& l \& m$ lul<").
} 
agitação, insônia entre outros (COPPO, 1988, p. 63). É preciso ressaltar, entretanto, que estes sinais deverão ser confrontados por um lado, com a capacidade ou incapacidade da pessoa em manter suas atividades cotidianas e, por outro, com explicações possíveis, coerentes com a visão de mundo dogon. Assim, o fato isolado de uma pessoa ver coisas que os outros não vêem ou não ouvem pode significar apenas que ela está em contato com os seres existentes mas não visíveis à maioria dos homens. Deste contato, ela pode obter tanto uma experiência negativa como positiva. Se a pessoa tem medo ( $n \&)$ pode perder-se (seu kinde kindu escapa), deixando o caminho aberto para que a doença entre. Outro destino é possível se a pessoa consegue fazer de sua experiência vivida um fator positivo, interpretando o episódio dentro dos contornos que o universo simbólico permite.

\section{Terapias}

Parece-nos difícil precisar os limites de um processo terapêutico. Onde começa a terapia? Não é possível desconsiderar os caminhos que levam à busca de sentido e as interpretações propostas por um familiar, adivinhos ou terapeutas. Os processos interpretativos pertencem ao mundo do tratamento propriamente dito.

A ação terapêutica parece ser, ela mesma, viva e em movimento permanente. Para compreender os processos terapêuticos é preciso apreender a importância de determinados aparatos ativos que são constituídos por um conjunto de objetos* fixados em lugares sacralizados. Eles são depositários e acumuladores de potências específicas e alvos de um conjunto de ritos que permitem sua continuidade histórica. Ruptura, abandono, descuido, roubo ou outro tipo de desordem destes aparatos (provocada por ação voluntária ou não), podem desencadear diversos eventos que põem em risco a pessoa, a família e até mesmo a sociedade.

Augé (1988, p. 22) afirma que estes objetosdeuses que mantêm uma relação de participação ontológica com os homens, formam uma unidade dinâmica e plural: "eles têm necessidade uns do outros: os homens de sua indulgência e os deuses das oferendas e sacrificios dos homens". Estes aparatos ativos podem ser individuais, pertencer a um grupo de ancestralidade comum, a uma linhagem ou um segmento de linhagem. Podem ser, ainda, adquiridos em situações específicas por uma pessoa, mas ao passar de uma geração à outra vão incorporando significados para a família, para a localidade e para aqueles que adquirem sua participação e pertencimento por meio das solicitações, sacrifícios e favores recebidos. A maior parte desses aparatos é para proteção, mas eles podem ser utilizados também para agredir. A ética de sua utilização é das pessoas e grupos, os objetos possuem em si a possibilidade da defesa ou do ataque. Diante de um "objeto", diante do "outro" (seja esse "outro" Deus, animal, homem, árvore ou pedra, fato natural ou fato social), não se coloca o alheamento, afirma Senghor (apud OLINTO, 2002).

O "objeto" não se desgarra de quem o conhece. O sujeito toca o objeto, apalpa-o, sente-o, simpatiza com ele, conhece-o, é ele. Acrescenta Senghor que o negro-africano não usaria a razão-olho da Europa, mas a razão-toque, a razão-amplexo do pensamento africano. Os diferentes elementos que constituem os aparatos ativos são, ao mesmo tempo, recursos (enquanto dotados de valor ou propriedades terapêuticas específicas) e mediação (enquanto veiculadores de comunicação e fornecedores de significados inteligíveis). O uso dos vegetais e animais evidencia a qualidade da relação homem-natureza; da coleta à ingestão dos medicamentos diversos cuidados e regras devem ser obedecidos para viabilizar a absorção das forças dos elementos necessários à pessoa debilitada. O especialista que age, por sua vez, no interior de parâmetros compartilhados pela sociedade.

Um conjunto de rituais integra a terapia. De um lado, os rituais propiciatórios e de purificação e de outro, aqueles ligados à aplicação dos medicamentos (fumigação, aspiração, ingestão).

A palavra é dotada de força intrínseca. Ibu $s<-$ a palavra que dá a vida - é carregada de qualidade de proteção e pode atuar em várias situações da vida cotidiana: para atrair a aceitação quando da chegada numa localidade estrangeira, contra a ação dos seres não visíveis, dos inimigos ou mau-olhados. O espaço terapêutico recobre, além dos rituais, o próprio cotidiano da pessoa em tratamento. Durante este período, a pessoa pode passar a viver com a família do terapeuta ou permanecer em seu ambiente doméstico. Após a cura, uma série de medidas é tomada para que a doença não volte e para agradecer o restabelecimento: rituais de

\footnotetext{
*Braceletes, cintos, pendentes, vestimentas, colares e objetos diversos fixados (plantados segundo o termo Dogon, pegu) ou não em espaços domesticados no povoado ou na casa ou na mata. Cada gelu possui sua palavra contendo regras de conduta, alimentares, encantamentos e ritos.
} 
fixação da doença e de agradecimento, definição de regras de conduta e alimentares. Em alguns casos, o agradecimento periódico é obrigatório, estabelecendo uma comunidade de adeptos.

Os ritos, juntamente com o local e os objetos que os integram, compõem o processo de socialização, neles a memória do grupo serve de base para a interpretação da experiência individual. Alguns deles atuam diretamente na formação da pessoa dogon, num movimento permanente e dinâmico que pode envolver desordem ou harmonização dos elementos que a constituem. Um exemplo é o jab\& - quando nasce um dogon este será seu primeiro locus, destinado a garantir sua proteção pessoal. Seu pai corta pedaços de unha das mãos e dos pés, cílios e cabelos que se depositam num ninho de passarinho. O ninho deve ser, então, colocado sobre uma pedra e esta recoberta com argila (KERVRAN, 1993, p. 200). Em cada povoado, podem coexistir aparatos diversos com variações significativas, é o caso pegu de fundação, do taba-amba (destinado à proteção da comunidade) e do binu-amba que está ligado à identidade profunda de um grupo de mesma ancestralidade.

Os ritos compõem formas de ação do homem sobre a natureza e sobre as relações dos homens entre si. Depositários de desejos e angústias, eles oferecem proteção pessoal e social assim como permitem agir sobre os desequilíbrios de diferentes tipos e origens. Podem ser fontes importantes para formação e manutenção da coesão e da solidariedade e, ao mesmo tempo, armas contra inimigos. Além disto, são associados a doenças provocadas por transgressões e bruxaria. Assim o "ritual africano, na medida em que concerne a individualidade humana, esforça-se ao mesmo tempo em identificar (e é sempre em termos de situação, de posição, de relação), em fixar e estabelecer como singularidade. Mas este último empreendimento é de longe o mais difícil' (AUGÉ, 1994, p. 35).

Para Houseman e Severi (1994, p.205-6) a ritualização define-se, antes de tudo, pelas formas relacionais que estabelece; esta rede de relações complexas que se materializam na ação ritual, alimentam a identificação dos implicados. Os autores enfatizam que uma pluralidade de relações que permanece separada na vida cotidiana (mutuamente excludentes) é condensada na ação ritual. No interior destas redes de relações tudo é simbólico. A ação ritual é aprendida através de um modo particular de imitação que comporta uma sistematização da imagem do outro. $\mathrm{O}$ ritual pode alimentar-se de um simbolismo que se manifesta preferencialmente através de linguagens nãoverbais, pois a linguagem verbal perde, no rito, o essencial de sua função comunicativa. As ações são o suporte para a tradução ritual das representações que contém gestos, palavras, imagens, relações, contexto, objetos. A prática ritual estabelece relações com a representação da experiência individual e da memória histórica, ela é "veículo de simbolização e instrumento de uma estratégia social" (HOUSEMAN; SEVERI, 1994, p. 195), além de instrumento para a construção da memória social.

\section{A palavra que se encerra}

Para finalizar é possível retomar alguns pontos que sintetizam a compreensão do adoecimento. As interpretações do mal aparecem através de duas grades linhas de interpretação. A primeira enfatiza a doença como manifestação da vontade de Amba e como destino. Esta é uma teoria de acobertamento e de busca de pacificação dos conflitos. A segunda, destaca as hipóteses que ligam a doença à ação nefasta de agentes sociais, uma noção baseada numa teria que coloca os conflitos sociais e interpessoais em primeiro plano. Nestes casos são, sobretudo, os conflitos ligados às relações matrimoniais e familiares e ao papel dos homens jovens na estrutura de poder que surgem como problemáticas mais freqüentemente referidas. Outros processos podem redefinir os limites e o sentido do bem-estar e da saúde. O medo $(n \&)$ repentino pode levar à pessoa a se perder (seu kinde kindu escapa) ou torná-la impura (contato com a morte), deixando o caminho aberto para que a doença entre. As transgressões e a quebra dos códigos de conduta configuram-se, também, como desordem. Trata-se, principalmente do desrespeito aos códigos de conduta interpessoais, da violação de um pacto ancestral, da violação das regras de conduta dos homens nas suas relações com a natureza visível e, também, com os seres não visíveis com os quais se deve compartilhar o espaço terrestre.

A loucura não é apreendida como mal de um corpo inerte a ser extirpado. As proposições enunciadas pelos terapeutas, adivinhos e doentes que conhecemos informam um sistema de compreensão e equacionamentos da problemática. Nelas os nexos entre manifestação da loucura e sociedade, entre processos terapêuticos e práticas ancestrais, entre real e imaginário, entre religiosidade e organização social não podem ser separados para serem conhecidos. Do mesmo modo, passado e futuro apresentam-se interpenetrados no presente, e a pessoa e o grupo permanecem indissociáveis ainda que em relações ao mesmo tempo complementares, concorrentes e antagônicas. 
BARROS, D.D. Mentally in the dogon society - Mali Republic. Rev. Ter. Ocup. Univ. São Paulo, v. 13, n. 2, p. 64-70, maio/ago. 2002.

\begin{abstract}
The survey providing the data was performed from July,1994 through August,1996, in the Bandiagara region, both the plateau and the cliff. The ways through which the knowledge about wede-wede and its meanings are organized has been discussed hereby, as well as the treatment and non-treatment possibilities offered to those considered mentally ill in the dogon society, Western Africa. The dogon society has got quite an extensive lexicon linked to the designation and understanding of the mental illnesses. On the other hand, they own a set of organized knowledge which is assessed and exercized mainly by the men and passed on from generation to generation within the same family root or acquired by means of revelation. Anyone who is considered mentally ill may be faced with differing fates: one may be sheltered, treated and reinserted into the society, or one may be treated and - once he/she cannot manage to find his/her position back in the social spheres - taken care of by some relative or friend. One may also be imprisoned at home or abandoned to wander aimlessly. In the latter case, the mentally ill are often to be found in markets, wandering along the roads and in the country-side villages.
\end{abstract}

KEYWORDS: Ethnopsychology. Mental disorders. Mental health. Culture. Occupational therapy/trends.

\title{
REFERÊNCIAS
}

AUGÉ, M. Le dieu objet. Paris: Flammarion, 1988.

AUGÉ, M. Le sens des autres: actualité de l'anthropologie. Paris: Fayard, 1994.

COPPO, P. (Org.). Medicine tradicionalle, psychiatrie et psychologie en Afrique. Roma: Il Pensiero Scientifico, 1988.

COPPO, P. Interpretation des maladies et leur classification dans la médecine traditionnelle dogon (Mali). II. Les troubles psychiques. Psychopatol. Afr., v. 26, n. 1, p. 35-60, 1994.

HAMPÂTÉ BÂ, A. Les voix de l'écriture. Itinéraire d'un fils du siècle. Paris: RFI-UNESCO, s.d. [document sonore: 68'43"]

HOUSEMAN, M.; SEVERI, C. Naven ou le donner à voir. Essai d'interpretation de l'action rituelle. Paris: CNRS/ Maison des Sciences de l'Homme, 1994.

KEVRAN, M. Dictionnaire dogon-français - région de
Bandiagara. Bruxelles: R. Deleu Éditieur, 1993.

LIONETTI, R. "Bana jugu": la malattia cattiva. Rapresetazioni del contagio percezione di una malattia nuova fra i guaritori tradizionali del Mali”. In: ENCONTRO "RIPENSARE l'AIDS", Bolonha, 29 abr. 1994. 17p. [mimeografado]

MOURÃO, F. A. A. Múltiplas faces da identidade africana. África, v. 18-9, n. 1, p. 5-21, 1995/96.

OLINTO, A. Leopold Senghor, o poeta do socialismo africano (on-line). Disponível em: <http://www.academia.org.br/2000/ artigo 72.htm>. Acesso em: nov. 2002.

SENGHOR. L. S. Ce que je crois: négritude, francité et civilisation de l'universel. Paris: Grasset, 1988.

SOW, I. Les structures anthropologiques de la folie en Afrique Noire. Paris: Payot, 1978. 